\title{
Global stroke statistics
}

Amanda G Thrift', Tharshanah Thayabaranathan', George Howard², Virginia J Howard ${ }^{3}$, Peter M Rothwell ${ }^{4}$, Valery L Feigin ${ }^{5}$, Bo Norrving ${ }^{6}$, Geoffrey A Donnan ${ }^{7,8, *}$ and Dominique A Cadilhac', $7, *$

\author{
Abstract \\ Background: Up to date data on incidence, mortality, and case-fatality for stroke are important for setting \\ the agenda for prevention and healthcare.
}

Aims and/or hypothesis: We aim to update the most current incidence and mortality data on stroke available by
country, and to expand the scope to case-fatality and explore how registry data might be complementary.

Methods: Data were compiled using two approaches: (1) an updated literature review building from our previous review and (2) direct acquisition and analysis of stroke events in the World Health Organization (WHO) mortality database for each country providing these data. To assess new and/or updated data on incidence, we searched multiple databases to identify new original papers and review articles that met ideal criteria for stroke incidence studies and were published between 15 May 2013 and 31 May 2016. For data on case-fatality, we searched between 1980 and 31 May 2016. We further screened reference lists and citation history of papers to identify other studies not obtained from these sources. Mortality codes for ICD-8, ICD9, and ICD-10 were extracted. Using population denominators provided for each country, we calculated both the crude mortality from stroke and mortality adjusted to the WHO world population. We used only the most recent year reported to the WHO for which both population and mortality data were available.

Results: Fifty-one countries had data on stroke incidence, some with data over many time periods, and some with data in more than one region. Since our last review, there were new incidence studies from 12 countries, with four meeting pre-determined quality criteria. In these four studies, the incidence of stroke, adjusted to the WHO World standard population, ranged from 76 per 100,000 population per year in Australia (2009-10) up to 119 per 100,000 population per year in New Zealand (2011-12), with the latter being in those aged at least 15 years. Only in Martinique (2011-12) was the incidence of stroke greater in women than men. In countries either lacking or with old data on stroke incidence, eight had national clinical registries of hospital based data. Of the 128 countries reporting mortality data to the WHO, crude mortality was greatest in Kazhakstan (in 2003), Bulgaria, and Greece. Crude mortality and crude incidence of stroke were both positively correlated with the proportion of the population aged ? 65 years, but not with time. Data on case-fatality were available in 42 studies in 22 countries, with large variations between regions.

Conclusions: In this updated review, we describe the current data on stroke incidence, case-fatality and mortality in different countries, and highlight the growing trend for national clinical registries to provide estimates in lieu of community-based incidence studies.

\section{Keywords}

Incidence, mortality, case-fatality, global, worldwide, stroke, burden, epidemiology

\section{Introduction}

With the growing world-wide burden of stroke, there is a continued need to understand the characteristics of the disease and its impact in various countries. As found with our first report on global stroke statistics published in the International Journal of Stroke (IJS) in 2014 having a common repository of the latest published information on major determinants of the burden of stroke worldwide that was focused on stroke incidence and mortality is important. ${ }^{1}$ We provide this update with additional information and consider this work as complementary to the information provided by the World Stroke Organization (WSO) and Global Burden of Disease (GBD) program.,3 As a flagship publication, we seek to regularly present comparative data for stroke in a readily accessible way, both in tabular and graphic form, using the latest available data at the time of publication which can be extracted from public records. We believe that such a compilation of data is a useful resource for all health care and related professions. This second report is part of an ongoing series to update information on stroke mortality and incidence; and provides new information on case-fatality and the issues of potentially outdated data for some countries. 


\section{Aims}

Our aims are to: (i) update our repository of the most recent country-specific data on stroke; (ii) determine where data on incidence, mortality and case-fatality are missing; and (iii) determine countries where data on incidence, mortality and case-fatality from stroke are out of date. A further exploratory aim was to identify whether nationally-representative clinical registry data were being routinely obtained in countries that had not undertaken an incidence study or had outdated stroke data to describe whether these were being used as a potential substitute for these data.

Figure 1. Screening and selection of articles with data on incidence or case-fatality.

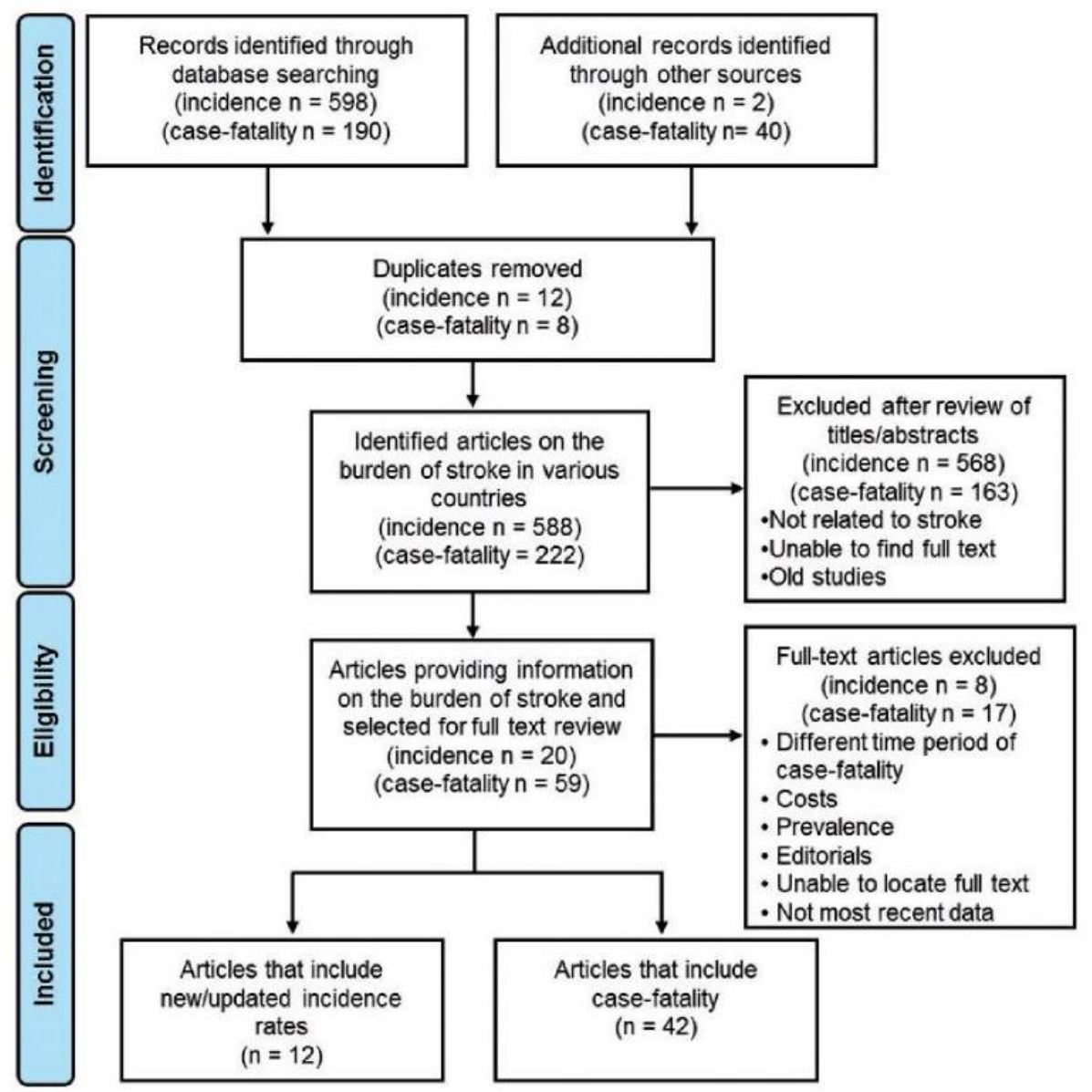




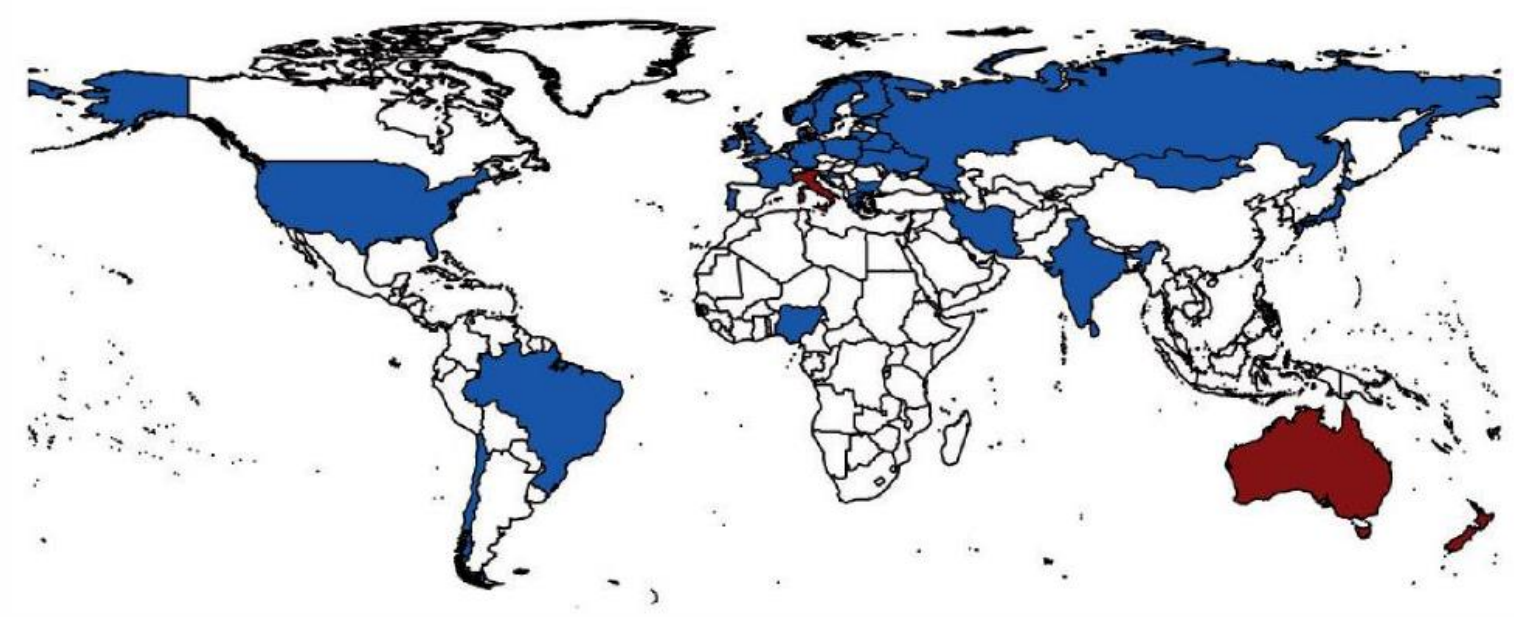

Figure 2. World map showing availability of studies with overall incidence. Old studies (in blue) indicate those that were included in the previous review, while new studies (in brown) indicate those published since that review. ${ }^{1}$ The map is based on crude and/or adjusted incidence of stroke irres pective of age restriction, or adjustment method. The countries highlighted are therefore different to those in Figure 6.

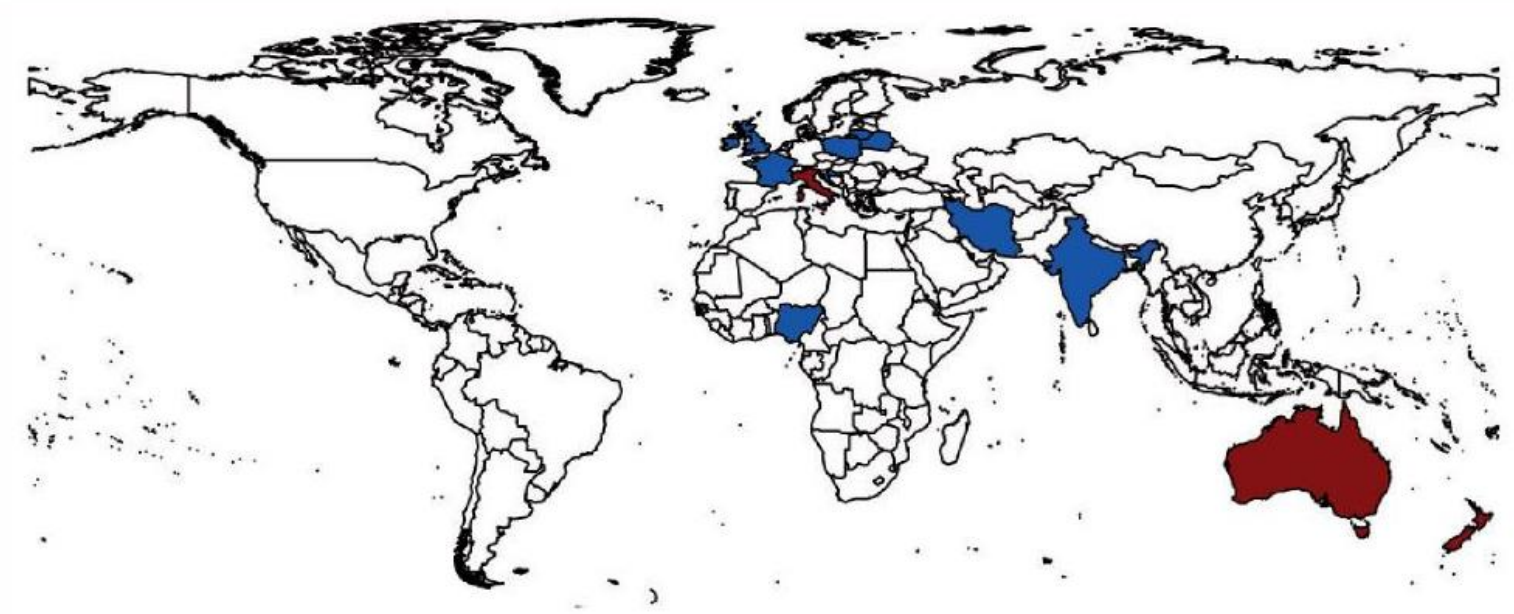

Figure 3. World map showing availability of studies with sex-specific incidence. The map is based on crude and/or adjusted incidence of stroke irrespective of age restriction, or adjustment method, hence it is different to Figure 6. Old studies are indicated in blue and new ones in brown

\section{Methods}

We sought to present incidence, mortality and case-fatality data for 205 countries (source: www.infoplease.com/countries.html) out of which 194 are recognized by WHO (source: www.who.int/countries/en/), 192 countries are members of the United Nations (source: www.un.org/en/members/), and 182 countries are recognized by the World Bank (source: www.world-bank.org/en/country). Incidence data were compiled by conducting an updated literature review with a major focus on original papers, using only population -based incidence studies. Additionally, case-fatality data from population-based studies were also compiled. Relevant data were also drawn from published systematic reviews on these topics. We also acquired mortality data from the World Health Organization (WHO) mortality database, using the most current available estimates of stroke mortality and the corresponding population denominator. 

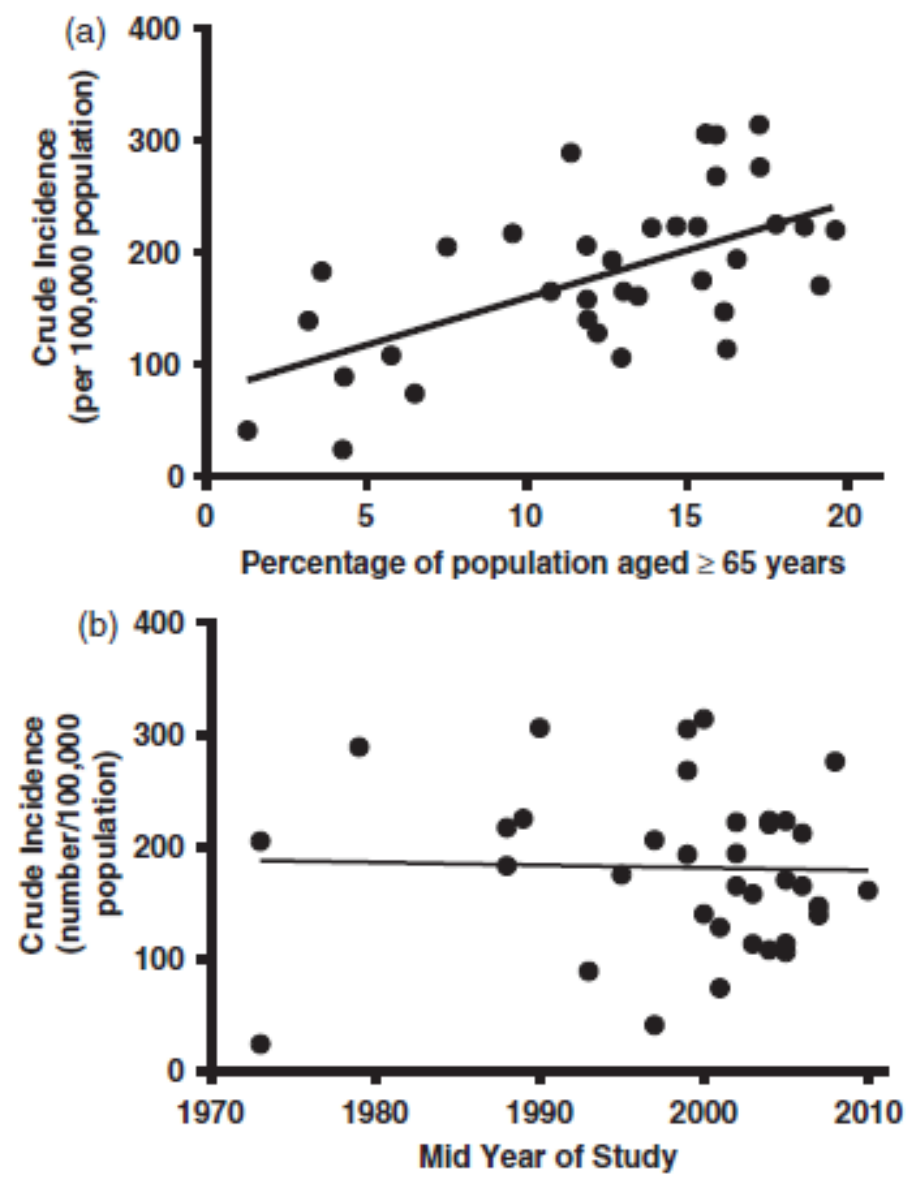

Figure 4. Crude incidence from stroke according to (a) the proportion of the population aged_65 years $\left(\mathrm{Y}_{1 / 48.442 * X p 75.32, \mathrm{p}<0.001)}\right.$ and (b) the mid-year that the study was conducted (Y1/4_0.2400*Xp661.4, $\mathrm{p} 1 / 40.86$ ). These are for all countries that have reported crude incidence, and for which population estimates were reported to the WHO. ${ }^{12,14,18-29}$

\section{Literature search and data extraction for incidence and case-fatality}

We searched multiple databases (Medline, Scopus, Pubmed, Google Scholar, WHO library, and WHO regional databases) to identify relevant original papers and review articles published from 15 May 2013 to 31 May 2016 for data on stroke incidence around the globe. Similarly, an extensive search was conducted from 1980 and until 31 May 2016 for data on case-fatality of stroke.

The search strategy developed was adapted from our previously published review article. ${ }^{1}$ Our pre-defined inclusion criteria comprised population-based studies that met, or potentially met, the ideal criteria (Supplementary Online Table 1), and a comprehensive determination of the overall incidence of stroke or on incidence among men and women separately. Ideal criteria included reports of first-ever in a lifetime stroke only to ensure that no figures were inflated by the inclusion of recurrent events. We also accessed papers where the incidence of any stroke type was reported, just in case the article contained overall incidence rates relevant to our aims. Data on types of stroke are not reported here. In addition, the search for case-fatality information was undertaken using terms such as case-fatality, mortality, and survival. We included case-fatality only from those studies that conformed to the ideal criteria for stroke incidence studies to ensure comparability between studies. Furthermore, only studies with published data on 7-day, 28-day, or 30-day case-fatality following stroke are included in this review. 
As previously, citations identified were first screened by title and abstract. After this first screening stage, the full text was read by a single reviewer (TT). We included only original papers and systematic reviews clearly meeting the inclusion criteria (as stated above).

To supplement the database searches, we screened the reference lists of these papers to identify any poten tially missing original papers or systematic reviews. Data were only included from reference lists on the incidence or case-fatality of stroke, which adhered to the same criteria as those for the database searches.

When new incidence or case-fatality data from one country were reported in more than one publication or online source, we linked the sources to prevent double-counting. For the heat maps on incidence, when there were data from the same country from both rural and urban regions, these countries were displayed as the mean value of these observations. Information from each paper was extracted by one reviewer (TT) and discussed among three reviewers (TT, AGT, DAC). All authors scrutinized the list of identified papers to as sess whether any known papers were missing.

Data on the location of stroke clinical registries that are considered in their country to represent a national standardized dataset for acute stroke care and outcomes were obtained from a recently published systematic review. ${ }^{4}$

\section{Incidence and mortality by age category}

We have previously provided details of the assessment of incidence and mortality versus age category. ${ }^{1}$ Briefly, for each country we undertook a regression analysis of crude incidence and/or mortality versus the proportion of the population aged $>65$ years. When possible, we used population data from the same year that incidence (and mortality) was assessed. When incidence was assessed over more than one year, the population data used was the mid-year of data collection. When the incidence studies spanned an even number of years, then the more recent of the two mid years was used. When there were no population data for the year in which the incidence study was conducted, we used the closest available year. For mortality, both population and mortality data were derived from the same year.

Because all of the new studies had data adjusted to the WHO World standard popu lation, we only report data using this standard. 


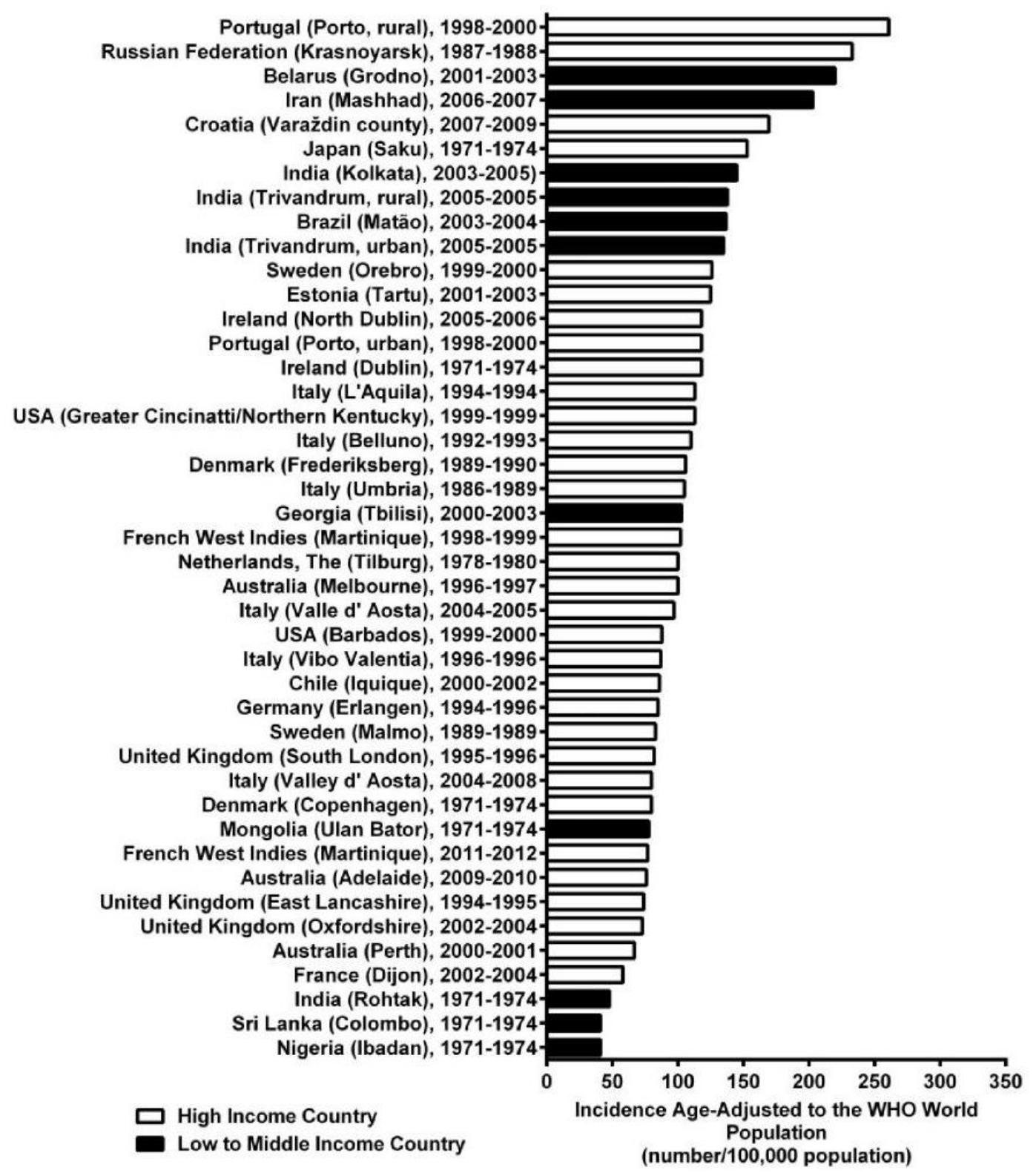

Figure 5. Incidence of stroke, adjusted to World Health Organization World population. 7,10,12,14,16,18-20,2226,30,31,34-39 High income countries are shown in the white bars, and low and middle income countries are shown in the black bars.

Collation and analysis of mortality data ability

Data for mortality and population denominators were obtained from the WHO website at www.who.int/ healthinfo/statistics/mortality_rawdata/en/. These data comprise deaths registered in country civil registration systems, with deaths coded by the national authority within each country. Population data are also provided by many of these countries. The latest data files from WHO were updated on 25 November 2015. Not all countries are listed in the mortality files provided by WHO. This is because (1) WHO does not receive mortality data from all countries; (2) some countries may provide data using non-standard codes; and (3) deaths may not be certified by a medical practitioner.

The files from WHO that we used include population denominators, country codes, and mortality data. The mortality codes used include those from ICD8, ICD9, and ICD 10 (Supplementary Online Table 2). 
Data on deaths from cerebrovascular disease were merged with the population denominators for the same year as that in which mortality was coded. Crude mortality of stroke was obtained by dividing the overall deaths from cerebrovascular diseases for each country by the total population. These were then multiplied by 100,000 to obtain crude mortality per 100,000 population. The same calculations were conducted for men and women separately. We then calculated age-adjusted death rates standardized to the WHO world population using the direct method. ${ }^{5}$

Where possible, adjustments were made using 5-year age bands. In some instances, data on mortality were only provided in 10-year age bands, and so 10-year age bands are used for these countries. Some countries also had different upper age bands for mortality, ranging between 65 years and 95 years. We used the best available data for each country and adjusted for age using the maximu m number of categories. We then removed all but the latest year data for each country.

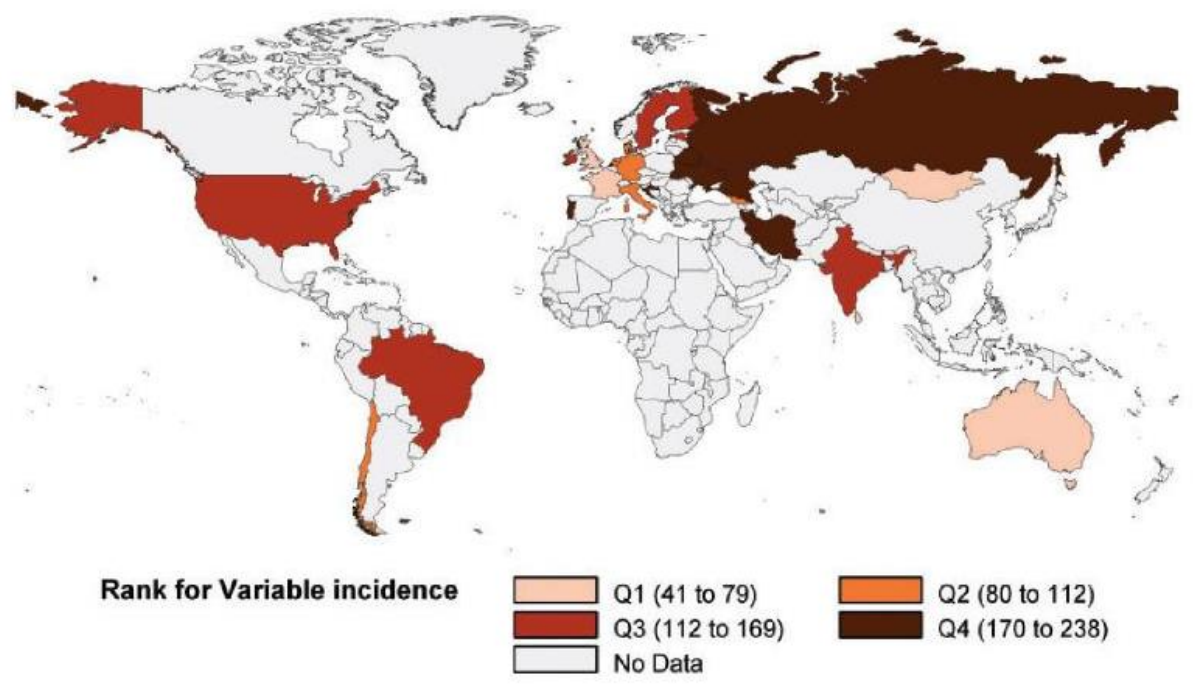

Figure 6. Heat map showing incidence of stroke adjusted to the WHO world population by quartiles. ${ }^{5}$

Table 1. Adjusted incidence of stroke in men and women. New studies are indicated by *.

Incidence rate per 100,000 population

(95\% confidence interval)

Standard

Country, study period

Men Women $\quad$ criteria met

\section{Age adjusted to the European standard} population

$356(334-377) \quad 236(222-250) \quad$ Ye

Croatia (Varaz din county), 2007-200925

$282(256-309.9)$

$181.1(165.6-197.6)$

No

France (Dijon), 2000-2006 34

$107.5(98.3-116.8)$

$68.9(62.7-75)$

Yes

Italy (Sesto Fiorentino), 2004-200673,74

$101.2(82.5-123)$

63 (48.5-80.7)

Yes

Italy (Valle d' Aosta), 2004-2005 20

159 (127-190)

$100(75-125)$

Yes

Kuwait, 1989, 1992, $1993^{75}$

$35.48(35.39-35.56)$

$16.66(16.59-16.73)$

No

Lithuania (Kaunas), $2004^{76}$

239.3 (209.9-271.6)

158.7 (135-185.4)

Yes

Poland (Warsaw), $2005^{26}$

$140(132-147)$

120 (114-127)

Yes

(continued) 


\begin{tabular}{|c|c|c|c|}
\hline \multirow{2}{*}{ Country, study period } & \multicolumn{2}{|c|}{$\begin{array}{l}\text { Incidence rate per } 100,000 \text { population } \\
(95 \% \text { confidence interval })\end{array}$} & \multirow{2}{*}{$\begin{array}{l}\text { Standard } \\
\text { criteria met }^{\mathrm{a}}\end{array}$} \\
\hline & $\overline{\text { Men }}$ & Women & \\
\hline $\begin{array}{l}\text { Spain (Castilla y Leo'n, Extremadura, and } \\
\text { Comunitat Valenciana regions), } 2005^{35}\end{array}$ & $99(81-117)$ & $66(53-80)$ & No \\
\hline Spain (Menorca), 2004-200673,74 & $116.3(96.1-139.5)$ & $65.8(50.9-83.8)$ & No \\
\hline *Spain (La Rioja), $2009^{16}$ & $206(187.7-224.4)$ & $139.3(127.0-151.5)$ & No \\
\hline United Kingdom (South London), 2004-2006 ${ }^{28}$ & $121.1(100.5-144.7)$ & $78.1(61.8-97.5)$ & Yes \\
\hline \multicolumn{4}{|l|}{ Age adjusted to Segi's World population } \\
\hline China (Beijing), $2000^{36}$ & $147.6(134.6-162.6)$ & $124(113-137.4)$ & No \\
\hline China (Changsha), $2000^{36}$ & $190(175.2-207.3)$ & $119.1(108.5-132.3)$ & No \\
\hline China (Shanghai), $2000^{36}$ & $87.3(78.5-98.2)$ & $68.1(61-77.3)$ & No \\
\hline France (Dijon), 2000-2006 34 & $72.5(65.9-79.1)$ & $47.3(45.5-52)$ & Yes \\
\hline Iran (Mashhad), 2006-2007 & $208(180-236)$ & $198(170-226)$ & Yes \\
\hline \multicolumn{4}{|l|}{$\begin{array}{l}\text { Age adjusted to WHO World standard } \\
\text { population }\end{array}$} \\
\hline *Australia (Adelaide), 2009-2010 & $91(73-112)$ & $61(47-78)$ & Yes \\
\hline Belarus (Grodno), 2001-2003 24 & $266(250-282)$ & $180(169-191)$ & Yes \\
\hline Bulgaria (Rural), $2002^{77}$ & $909(729.67-1132.41)$ & $667(529.24-840.61)$ & No \\
\hline Bulgaria (Urban), $2002^{77}$ & $597(491.2-725.59)$ & $322(255.14-406.637)$ & No \\
\hline Croatia (Varaz din county), 2007-200925 & $213.1(194-233.3)$ & $137.6(126.3-150.9)$ & No \\
\hline India (Trivandrum, rural), $2005^{31}$ & $163.4(122.4-204.4)$ & $115.3(83-147.6)$ & Yes \\
\hline India (Trivandrum, urban), $2005^{31}$ & $141.7(122.1-161.3)$ & $130.1(113.3-146.9)$ & Yes \\
\hline India (Kolkata), 2003-200578 & $117.1(87.8-152.6)$ & $178.0(102.4-223.2)$ & Yes \\
\hline Italy (Valle d' Aosta), 2004-2005 20 & $122(94-150)$ & 77 (55-99) & Yes \\
\hline *Italy (Valle d' Aosta), 2004-20087 & $100(89-112)$ & $62(53-71)$ & Yes \\
\hline *Japan (Iwate State) $)^{15}$ & $190(172-209)$ & $104(91-118)$ & No \\
\hline *Martinique (Caribbean) $)^{14}$ & $90(79-101)$ & $69(60-78)$ & Yes \\
\hline *New Zealand (Auckland) ${ }^{10}$ & $129(120-138)$ & $110(103-119)$ & Yes \\
\hline${ }^{*}$ Spain (La Rioja) ${ }^{16}$ & $131.0(119.3-142.6)$ & $86.2(78.6-93.8)$ & No \\
\hline
\end{tabular}

${ }^{a}$ Standard criteria $1 / 4$ multiple overlapping sources, World Health Organization definition of stroke, incidence cases, no upper age limit, and prospective design. 


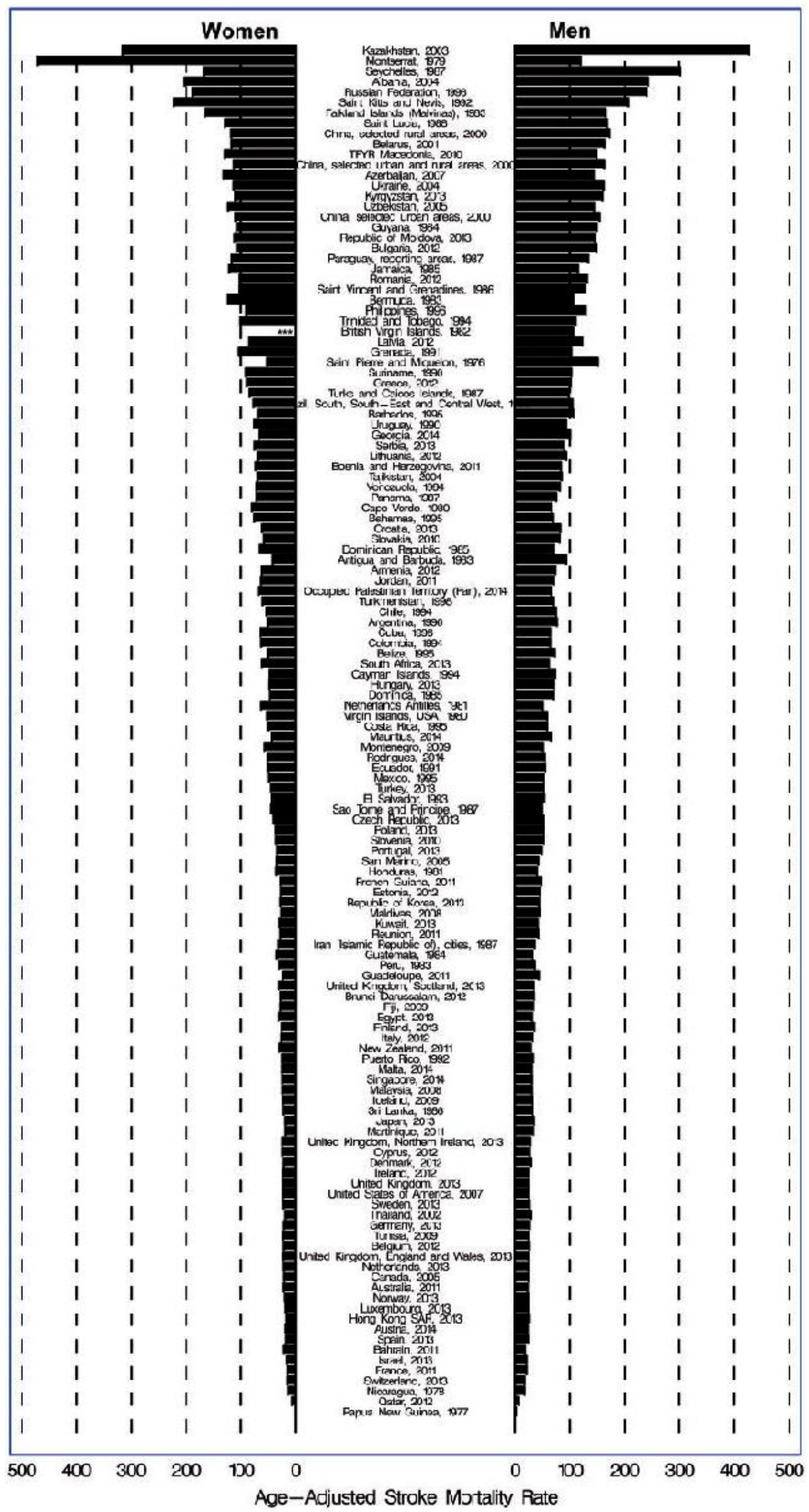

Figure 7. Crude mortality from stroke in the most recent year reported to the World Health Organization, ordered according to the average mortality for men and women. Note that mortality data for China are for selected regions only and represent $<10 \%$ of all deaths in the country. 

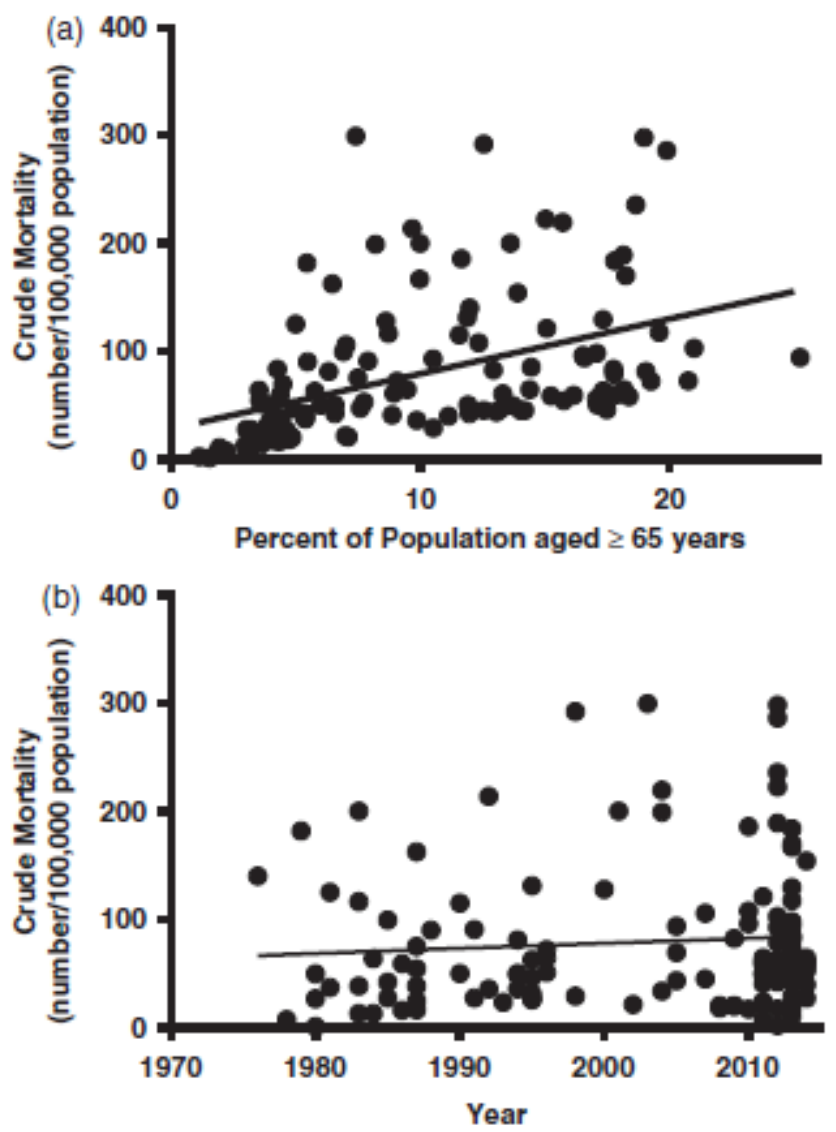

Figure 8. Crude mortality from stroke according to (a) the proportion of the population aged at least 65 years $(\mathrm{Y}$ $=5.091 * \mathrm{X} \mathrm{p} 28.08, \mathrm{p}<0.0001)$ and $(\mathrm{b})$ the year $\left(\mathrm{Y}=0.4675^{*} \mathrm{X}-856.90, \mathrm{p}=0.35\right)$. These are for all countries that have reported mortality to the World Health Organization, and are for the most recent year reported for each individual country.

\section{Comparison of crude incidence and crude mortality}

We assessed the relationship between the crude incidence and mortality for each country, using the same year for incidence and mortality, where possible. When the study was conducted over more than one year, we used population data from the middle year of the study, and when there was an even number of years the latter of the two mid years was used. When countries had not reported population data to WHO, even when mortality data were present, these countries were excluded. For countries that had no population data for the year in which the incidence study was conducted, but had population data for other years, the closest available year was used.

\section{Results}

Overall there were 12 countries in which new incidence data were reported. Of the 128 countries in which mortality data had been reported to the WHO, in $57(44.5 \%)$ the figures were new or updated since our last review. In addition, data on case-fatality were reported for 22 countries.

\section{Incidence}

The literature search yielded 600 publications (see Figure 1 for selection process). In the first stage of screening, we retrieved 20 potential new articles on stroke incidence. In 12 of these articles, total crude stroke incidence was reported ${ }^{6-17}$ with four conforming to our search criteria. In nine articles, separate rates were reported for 
men and women, ${ }^{7-10,12-16}$ with four conforming to our strict criteria. Of those conforming to our strict methodological standards all were age-adjusted to the WHO population for both overall stroke incidence and sex-specific incidence rates..$^{7,10,12,14}$ In Figure 2, the location of these new published studies are highlighted in brown for overall stroke incidence, while Figure 3 shows all countries that provided sex-specific incidence rates. The updated data on crude incidence of stroke, including both old and new studies, varies gre atly among countries (Figure 4, Supplementary Online Table ${ }^{3) \cdot 12,14,18-29}$ Of the studies identified since our last review ${ }^{1}$ that met our criteria, the largest crude stroke incidence rate was observed in Italy 2004-8) at 212/100,000 population per year, ${ }^{7}$ with this population having a large proportion of people aged 65 years (19\%; Figure 4(a)). ${ }^{15}$ In contrast, Saku (Japan) had a relatively high crude incidence of stroke (205 per 100,000 per year) in the presence of a small population at risk (7.5\% aged 65 years; Figure $4(\mathrm{a})) .{ }^{22}$ Similar data are available for men and women in some regions (Supplementary Online Table 4).7-10,12-16,18,19,23-27,29-33 There was no difference in incidence according to the year that the study was conducted (Figure 4(b)).

Using the WHO World standard population, the age adjusted incidence rates of the studies identified since our last review, and meeting our strict criteria, range from 76 per 100,000 population per year in Adelaide, Australia (2009-10) to 119/100,000/year in Auckland, New Zealand (see Figures 5 and 6, and Supplementary Online Table 5).7,10,12,14,16,18-20,22-26,30,31,34-39 This latter study was age-adjusted to the population aged 15 years and so incidence rates are greater than would occur if all age groups were included. New age-adjusted stroke incidence rates are greater in men than in women in all countries (Table 1). ${ }^{14}$

\section{Mortality}

Since our last review, where the most recent data available were for 2011, there are now new data for 2012 (14 countries), 2013 (28 countries), and 2014 (67 countries; see Supplementary Online Table 6).

Kazhakstan remained the country with the greatest crude stroke mortality (number of deaths per 100,000 population per year) but there were no new data for this country since 2003. New data from Bulgaria and Greece (both 2012) were also similarly high (298/100,000 population per year for Bulgaria and 285/100,000 per year for Greece; Figure 7 and Supplementary Online Table 7). Countries with new mortality at the lower end of the spectrum included Qatar (2.2/100,000/year in 2012), Bahrain (7.5/100,000/ year; 2011), and Kuwait (10.4/100,000/year; 2013).

Countries such as Austria and Switzerland have very low stroke mortality rates despite a large proportion of the population who are aged 65 years (Figure 8(a)). The largest mortality rates in countries with a relatively small proportion of the population aged 65 years include Montserrat (1979), the Seychelles (1987), and the British Virgin Islands (1982), but these data are relatively old, and the latter is based on a very small population.

The positive as sociation between the year that the mortality data were collected and their crude mortality rates that we reported in our last review is no longer evident (Figure 8(b)), suggesting that crude mortality is not increasing.

When assessing mortality rates for stroke adjusted to the new world population, the countries with the 10 largest rates remain the same as in our past review. None of these countries have provided updated data to WHO, and so these data are relatively old (Figures 9 and 10; Supplementary online Table 7).

There were 29 countries that had both crude incidence of stroke reported (all ages included) as well as mortality data provided to the WHO. There were an extra seven observations, as some countries had more than one incidence study in more than one region. There is a strong positive as sociation between incidence and mortality from stroke (Figure 11). Even when removing the two regions of Portugal with the greatest incidence of stroke, the regression shows a strong association and a steep slope $(\mathrm{Y}=0.5652 * \mathrm{X}$ p 109.8, $\mathrm{p}=0.0002)$. 


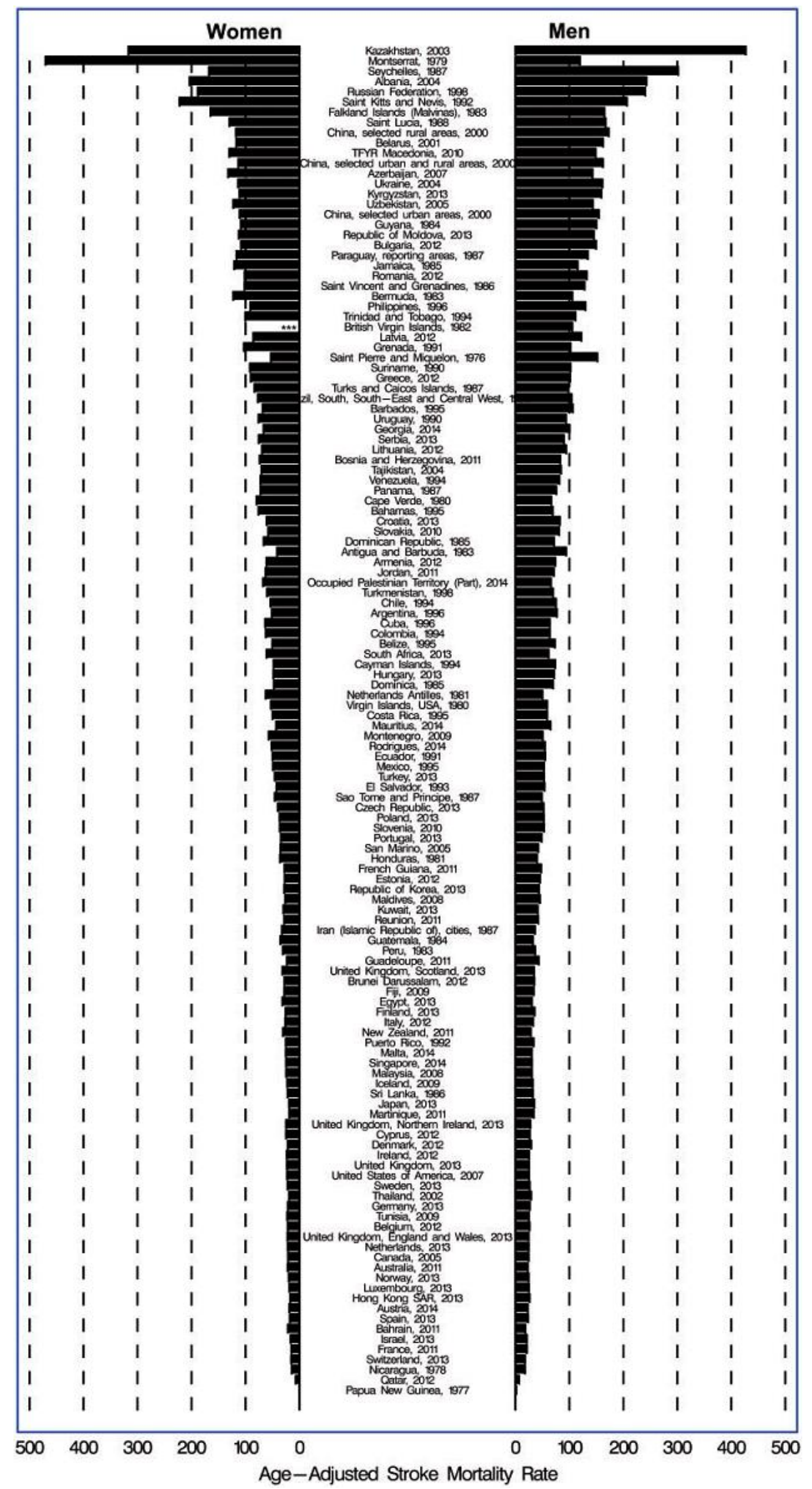

Figure 9. Age-

adjusted

mortality from

stroke in the

most recent year

reported to the

World Health

Organization,

ordered

according to the

average mortality

for men and

women. Note

that mortality

data for China

are for selected

regions only and represent $<10 \%$

of all deaths in

the country. 


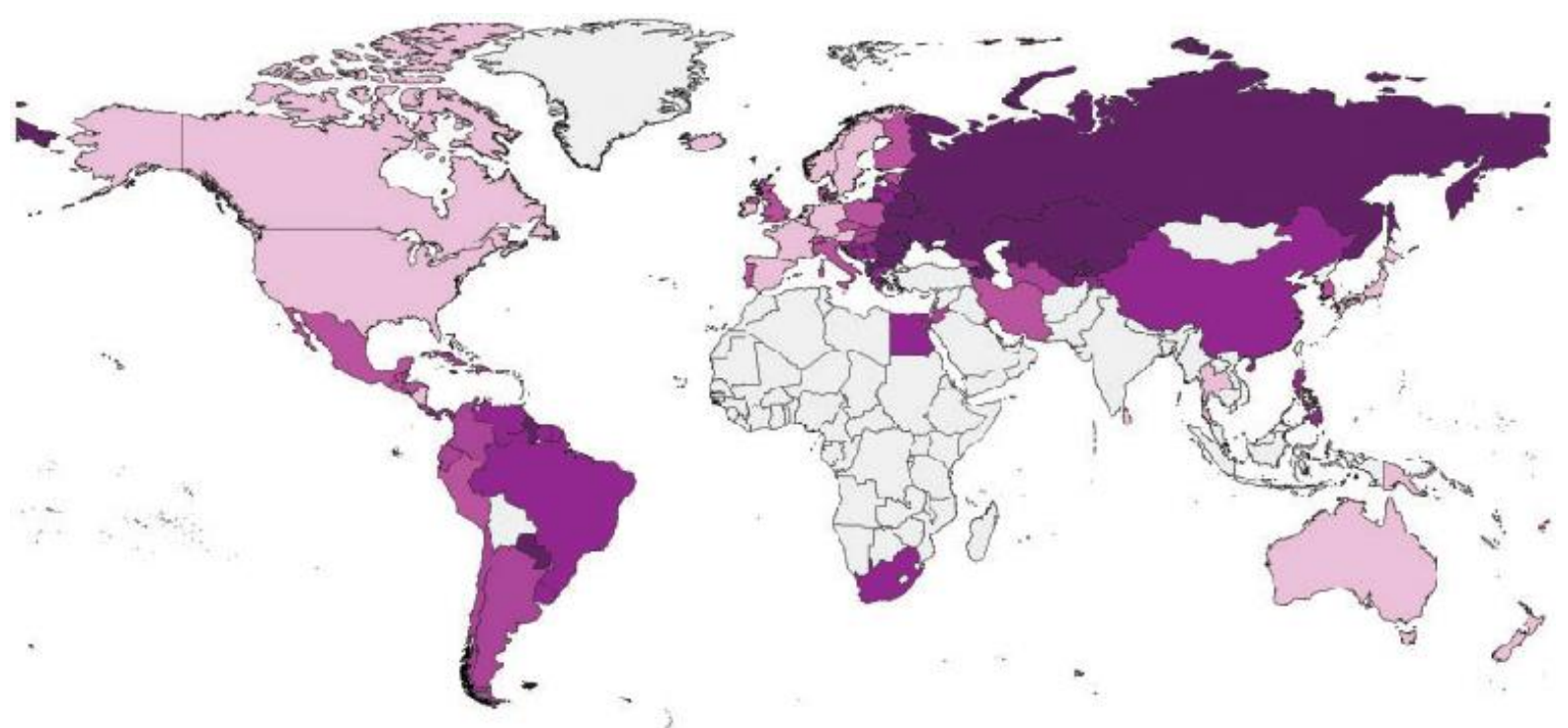

Rank for Variable mortality
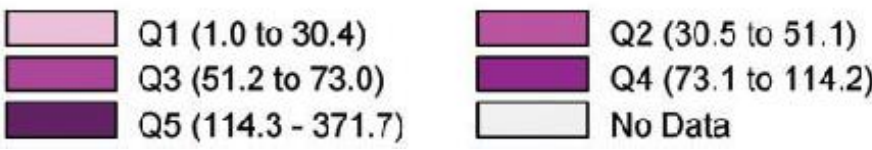

Figure 10. Heat map showing mortality from stroke adjusted to the WHO world population, by quintiles. ${ }^{5}$

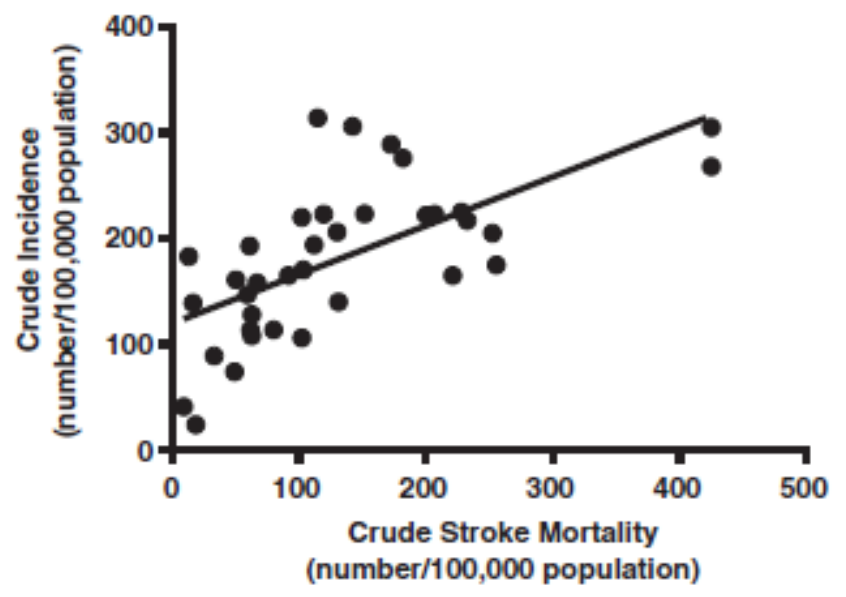

Figure 11. Regression of crude mortality from stroke versus incidence. These are for all countries that have reported mortality to the World Health Organization, and also have assessed the incidence of stroke for a similar year $\left(Y^{1} / 40.4616^{*} \mathrm{Xp} 119.9, \mathrm{p}<0.0001\right)$. 


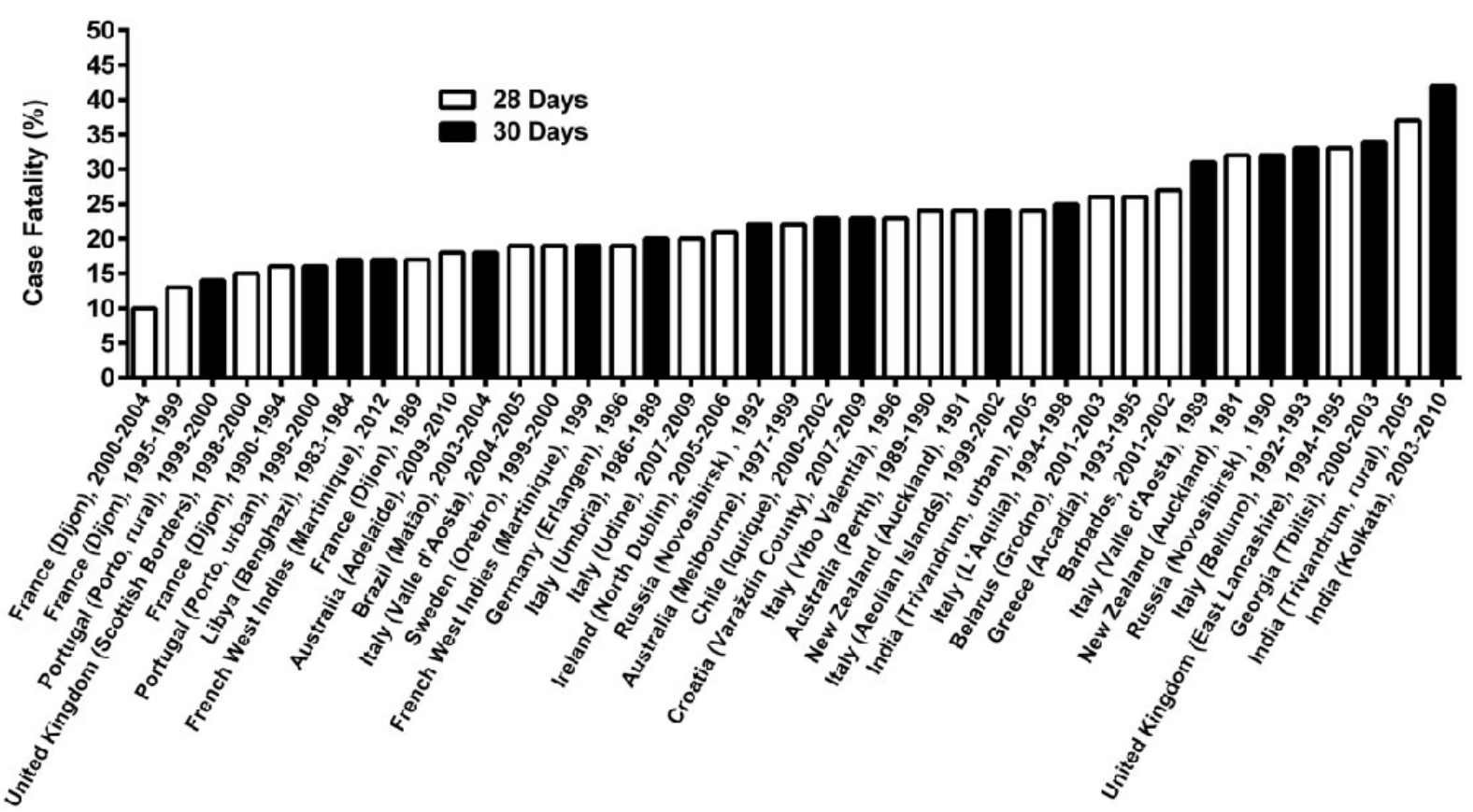

Figure 12. Overall 28-day and 30-day case-fatality of stroke that are reported in countries. ${ }^{7,12,14,19,23-25,31,37,38,40-60}$

\section{Case-fatality}

The literature search yielded 222 publications (see Figure 1 for selection process). In the first stage of screening, we retrieved 59 potential articles and 42 provided usable data. In two of these, overall 7-day case-fatality were reported, being 13.1\% in Barbados (2000) and 33\% in Kolkata (2003- 2010). ${ }^{19,40}$ In 20 studies, overall casefatality was reported at 28 days, $7,12,19,23,24,31,37,40-51$ and 16 provided 30 -day case-fatality..$^{14,25,38,45,52-60}$ Separate figures for men and women were reported for 17 studies. ${ }^{14,24,25,44,50,51,55,57,58,61-63}$ Among these articles, 10 had 28-day sex-specific case-fatality,24,44,50,51,61-63 and the remainder had 30-day sex-specific casefatality. $14,25,55,57,58$

The data on case-fatality of stroke provide evidence for considerable variation among countries despite the strict criteria for inclusion (Figures 12 and 13). The greatest overall 28-day case fatalities were observed in India at approximately $37-42 \%$ at 28 days. ${ }^{31,40}$ The least case-fatality was observed in Dijon (2000-2004) at $10 \%$ (28 days; Table 2). ${ }^{43}$ 

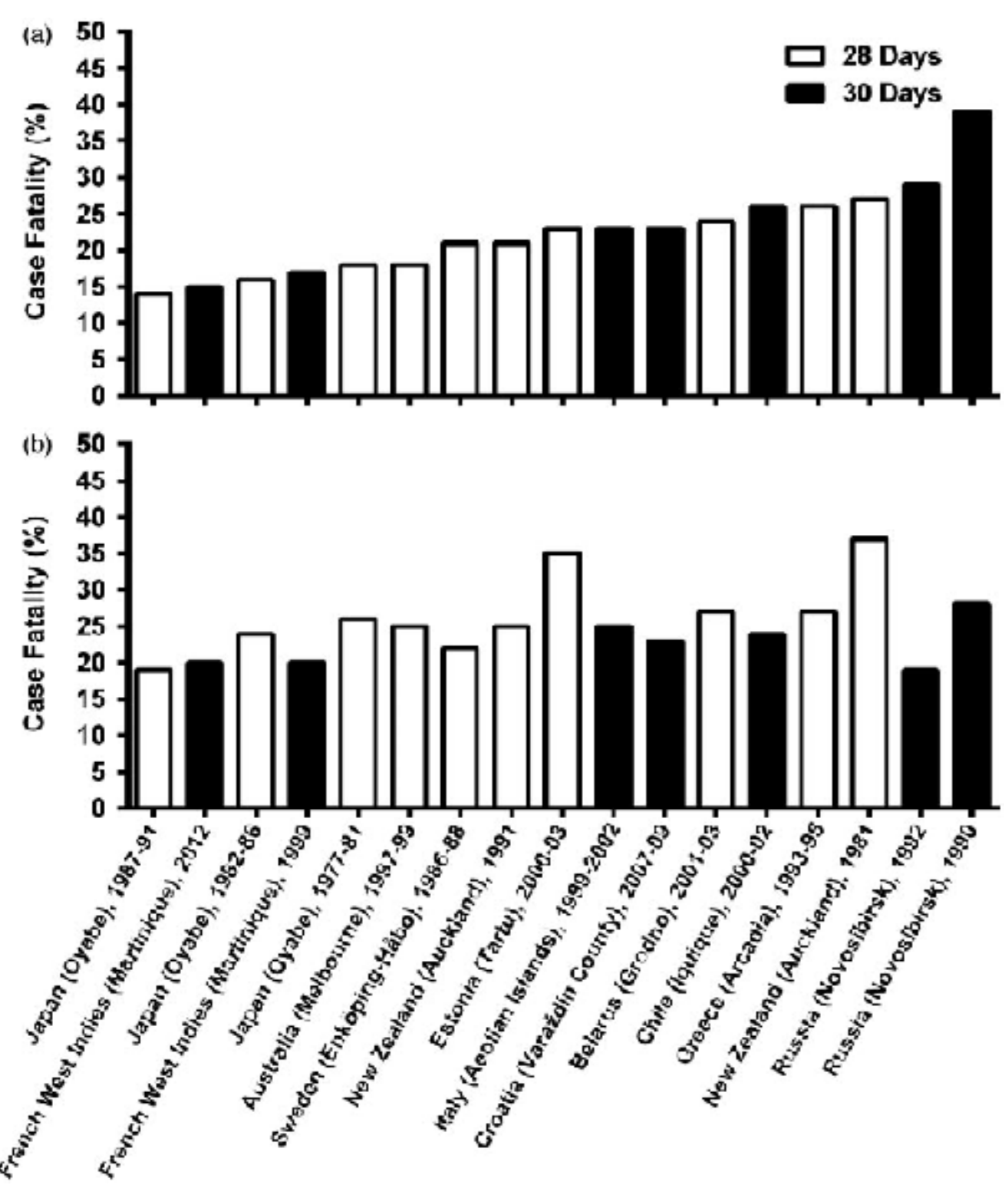

Figure 13. Comparis on of gender-specific 28-day and 30-day case-fatality of stroke that are reported in countries. ((a) men, (b) women)14,24,25,44,50,51,55,57,58,61-63

Table 2. Crude case-fatality $(\%)$ of stroke in countries: reported at $28-30^{\mathrm{a}}$ days.

\begin{tabular}{|c|c|c|c|c|c|c|}
\hline Country & \multicolumn{2}{|c|}{ Overall \% (CI) } & \multicolumn{2}{|c|}{ Men \% (CI) } & \multicolumn{2}{|c|}{ Women \% (CI) } \\
\hline Australia (Adelaide), $2009-10^{12}$ & 18 & $(14-24)$ & & & & \\
\hline Australia (Melbourne), 1997-9950 & 22.5 & $(20.0-25.1)$ & 18.3 & $(14.7-21.8)$ & 25.8 & $(22.3-29.4)$ \\
\hline Australia (Perth), 1989-9041 & 24 & $(20-28)$ & & & & \\
\hline Belarus (Grodno), 2001-200324 & 26.1 & & 24.4 & & 27.8 & \\
\hline Brazil (Matao), 2003-04 38a & 18.5 & $(10.7-28.7)$ & & & & \\
\hline
\end{tabular}


Page 16

\begin{tabular}{|c|c|c|c|c|c|c|}
\hline \multirow{2}{*}{$\begin{array}{l}\text { Country } \\
\text { Chile (Iquique), 2000-0257a }\end{array}$} & \multicolumn{2}{|c|}{ Overall \% (CI) } & \multicolumn{2}{|c|}{ Men \% (CI) } & \multicolumn{2}{|c|}{ Women \% (CI) } \\
\hline & 23.3 & $(18.1-29.5)$ & 26.2 & $(18.9-35.3)$ & 24.2 & $(16.4-34.4)$ \\
\hline Croatia (Varaz din County), 2007-0925a & 23.5 & & 23.6 & & 23.4 & \\
\hline Estonia (Tartu), $2000-03^{63}$ & & & 23 & & 35 & \\
\hline France (Dijon), $1989^{43}$ & 17.8 & $(15.4-20.5)$ & & & & \\
\hline France (Dijon), 1990-9443 & 16.6 & $(14.4-19.1)$ & & & & \\
\hline France (Dijon), 1995-99 & 13.9 & $(11.8-16.3)$ & & & & \\
\hline France (Dijon), 2000-0443 & 10 & $(8.3-12.1)$ & & & & \\
\hline French West Indies (Martinique), 1998-9914a & 19.3 & $(15.5-24.1)$ & 17.9 & $(12.9-24.8)$ & 20.7 & $(15.3-28.0)$ \\
\hline French West Indies (Martinique), 2011-12 & 17.6 & $(13.3-23.4)$ & 15.1 & $(9.2-24.6)$ & 20.6 & $(14.8-28.7)$ \\
\hline Georgia (Tbilisi), 2000-0360a & 34.8 & $(28.7-41.3)$ & & & & \\
\hline Germany (Erlangen), 1994-9649 & 19.4 & $(16.1-23.3)$ & & & & \\
\hline Greece (Arcadia), 1993-9551 & 26.6 & $(22.9-32.2)$ & 26.3 & $(21.3-31.1)$ & 27.1 & $(21.4-32.6)$ \\
\hline India (Kolkata), 2003-10 & 42 & $(38.6-45.6)$ & & & & \\
\hline India (Trivandrum, rural), $2005^{31}$ & 37.1 & & & & & \\
\hline India (Trivandrum, urban), $2005^{31}$ & 24.5 & & & & & \\
\hline Ireland (North Dublin), 2005-0623 & 21 & $(17.6-24.9)$ & & & & \\
\hline Italy (Aeolian Islands), 1999-200258a & 24.2 & $(19.2-36.8)$ & 23.1 & $(9.0-43.7)$ & 25 & $(12.2-42.2)$ \\
\hline Italy (Belluno), 1992-9356a & 33 & & & & & \\
\hline Italy (L'Aquila), 1994-9845a & 25.6 & $(22.8-28.7)$ & & & & \\
\hline Italy (Udine), 2007-0948 & 20.6 & $(17.8-23.8)$ & & & & \\
\hline Italy (Umbria), $1986-89^{59 a}$ & 20.3 & $(16.2-24.3)$ & & & & \\
\hline Italy (Valle d'Aosta), $1989^{54 a}$ & 31 & & & & & \\
\hline Italy (Valle d'Aosta), 2004-087 & 19 & & & & & \\
\hline Italy (Vibo Valentia), $1996^{46}$ & 23.7 & $(19.0-28.3)$ & & & & \\
\hline Japan (Oyabe), 1977-8162 & & & 18 & $(19.2-21.8)$ & 26.8 & $(22.1-31.5)$ \\
\hline Japan (Oyabe), 1982-86 & & & 16.3 & $(12.2-19.8)$ & 24.5 & $(19.4-29.6)$ \\
\hline Japan (Oyabe), 1987-91 ${ }^{62}$ & & & 14.2 & $(10.4-17.4)$ & 19.1 & $(14.9-23.3)$ \\
\hline Libya (Benghazi), $1983-84^{52 a}$ & 17.3 & & & & & \\
\hline New Zealand (Auckland), $1981^{44}$ & 32.2 & $(28.4-36.5)$ & 27.1 & $(21.7-32.6)$ & 37.6 & $(31.8-43.5)$ \\
\hline New Zealand (Auckland), $1991^{44}$ & 24.1 & $(21.4-26.7)$ & 21.9 & $(18.1-25.7)$ & 25.8 & $(22.3-29.4)$ \\
\hline Portugal (Porto, rural), $1999-2000^{53 a}$ & 14.6 & $(10.2-19.3)$ & & & & \\
\hline Portugal (Porto, urban), 1999-200053a & 16.9 & $(13.7-20.6)$ & & & & \\
\hline Russia (Novosibirsk), $1990^{55 a}$ & 32.3 & $(25.8-38.8)$ & 39.4 & $(27.0-51.7)$ & 28.4 & $(20.7-36.2)$ \\
\hline Russia (Novosibirsk), 199255a & 22.7 & $(17.7-27.7)$ & 29.1 & $(19.2-39.0)$ & 19.1 & $(13.3-24.9)$ \\
\hline Sweden (Enko"ping-Hâbo), 1986-88 & & & 21 & & 22 & \\
\hline
\end{tabular}




\begin{tabular}{llll}
\hline \multicolumn{1}{c}{ Country } & Overall \% (CI) & Men \% (CI) & Women \% (CI) \\
\hline Sweden (Orebro), 1999-2000 & 19 & \\
United Kingdom (Scottish Borders), 1998- & 15.9 & \\
$2000^{37}$ & 33.8 & \\
United Kingdom (East Lancashire), 1994-9547 & 27.8 & $(24.9-34.8)$ \\
USA (Barbados), 2001-02 ${ }^{19}$ & & \\
a30-Day case-fatality.
\end{tabular}

\section{Discussion}

In this updated review of global stroke statistics, we include evidence from new studies of stroke incidence $(\mathrm{n}=$ 12) and important updates of mortality data from 57 countries available from WHO. We also report case-fatality data as a new focus of attention. Important ongoing disparities in stroke incidence, mortality, and case-fatality were evident and provide an impetus for more effective prevention and improved clinical man agement of stroke.

Incidence rates presented in our review differ somewhat to those presented in the GBD Study (Figure 14), even though both were adjusted to the WHO World population. ${ }^{64}$ These differences highlight the different aims of these studies. The GBD was undertaken to provide estimates of stroke in all regions using a systematic approach, and has the added advantage of enabling comparison across diseases. In contrast, our approach enabled us to identify countries with the most recent data on stroke incidence obtained using ideal meth -ods, ${ }^{65}$ and has the advantage of highlighting countries where data are lacking or out of date. Both approaches enable one to determine where there are hotspots in stroke occurrence. High quality data are needed to help plan and develop approaches to improve access to preventive strategies and stroke care. Knowing where important data are lacking, outdated or even where a country is ranked might help facilitate more research or greater policy attention in this field. This is important so that modifiable strategies that are within the control of health funders and providers of health care may be tackled using a data-driven approach. Recently, the WSO has provided guidelines and tools to support countries to review their health system and address improvements to the quality of care they provide for people who experience stroke. ${ }^{66} \mathrm{In}$ addition, there are more options now for primary prevention monitoring accessible to consumers which may help to encourage risk factor modification. ${ }^{67} \mathrm{In}$ particular, it is emphasized by WSO that although there are differences in resource availability among countries, it should always be feasible to increase stroke awareness, education, prevention, and treatment. By having standardized methods to compare and contrast countries over time it is possible to monitor progress. This includes the use of WSO Health System Indicators ${ }^{66}$ recently showcased in the paper by Tse and colleagues whereby Australia, Singapore, and the USA ${ }^{68}$ were compared on how well they align with the WSO Health System Indicators and the sources of routine data available to make such comparisons. Our report herein provides important information for two of the 10 WSO Health System Indicators: stroke incidence rates adjusted for age and sex in the population; and case fatality at 7 and 30 days.

Comparison of data for case-fatality provides two main challenges. First, case-fatality figures are presented in varying time periods; at 7 days, 28 days, and 30 days, making it difficult to compare outcomes across regions. Secondly, crude case-fatality figures do not take into account the fact that strokes occur at different ages across countries, and so greater case-fatality may actually reflect the age at which strokes are occurring and not differences in the management of stroke. Recommendations to provide data in stand ard time epochs, and providing case-fatality by 10 -year age groups, would ensure better comparability among studies, including estimates of age-adjusted case-fatality figures.

Interestingly, we have noted that where incidence studies are not being undertaken or where incidence, casefatality or mortality data are old, alternate methods of data collection are occurring in the form of clinical registries. In a recent systematic review, registries that were considered in their country to represent a national standardized dataset for acute stroke care and outcomes were summarized whereby 28 national stroke registries 
from 26 countries were identified. ${ }^{4}$ When we overlaid the location of these registries to where the identified incidence studies had been undertaken we noted that in several countries this provided a reasonable explanation for why potentially more resource intensive community-based stroke incidence studies may not have been conducted or repeated (Figures 15 and 16). We accept that the majority of the included registries may not have full national coverage and in some countries there are large registries containing data on stroke that may inclu de several stroke-mimicking conditions or be regionally based for example Catalonia. ${ }^{4,69}$ However, these data provide an indication of changing methods of disease surveillance that may also be capturing aspects of the quality of care. In addition, hospitalization ratios differ between countries (e.g. ' $90 \%$ in Sweden, ${ }^{70}$ ' $10 \%$ in Japan). ${ }^{71}$ Therefore, registries may be a better proxy for important epidemiological measures in countries where the majority of incidence cases are treated in hospital.

The main strengths of this review include its comprehensiveness, lack of fixed time period restrictions, and the use of high quality studies that met strict criteria. The limitations include that we were only able to provide information using the available data reported for a country and the methods used in obtaining these data vary. This potentially makes any direct comparisons less reliable. Further, since the incidence and case fatality data are often obtained from one geographical region and may not be representative of other geographical regions within a country, this is a potential source of over- or underestimation of stroke incidence rates and case-fatality. Because mortality rates have been declining over time, ${ }^{2,64}$ the rank position of a country may also be influenced by the currency of their data, differences in data collection policies for reporting deaths, and the potential misclassification of causes of death. ${ }^{72}$ 


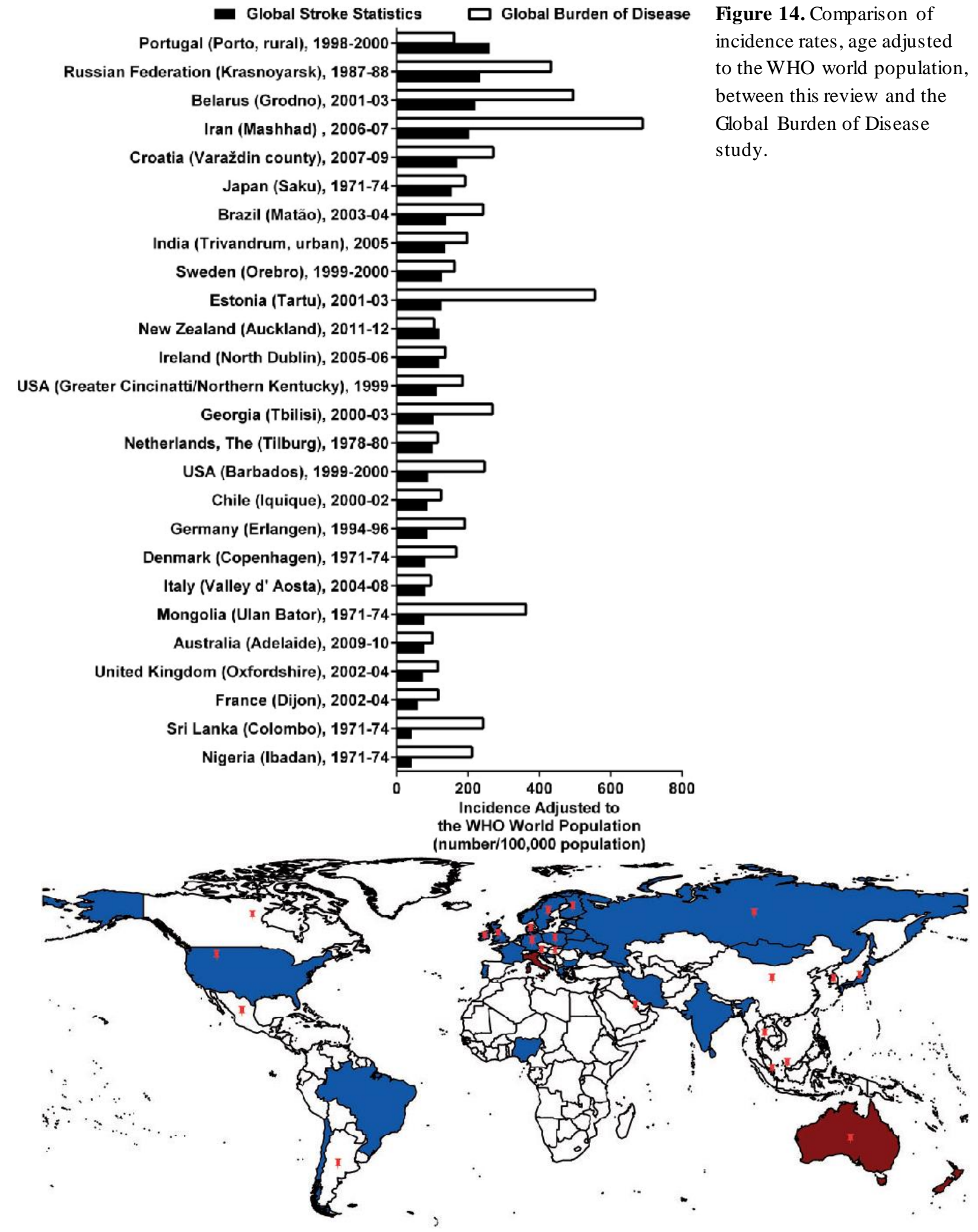

Figure 15. World map showing availability of studies with overall incidence and national registries (pins). These include studies with either crude incidence and/or adjusted incidence figures irrespective of age restriction, or adjustment method. 


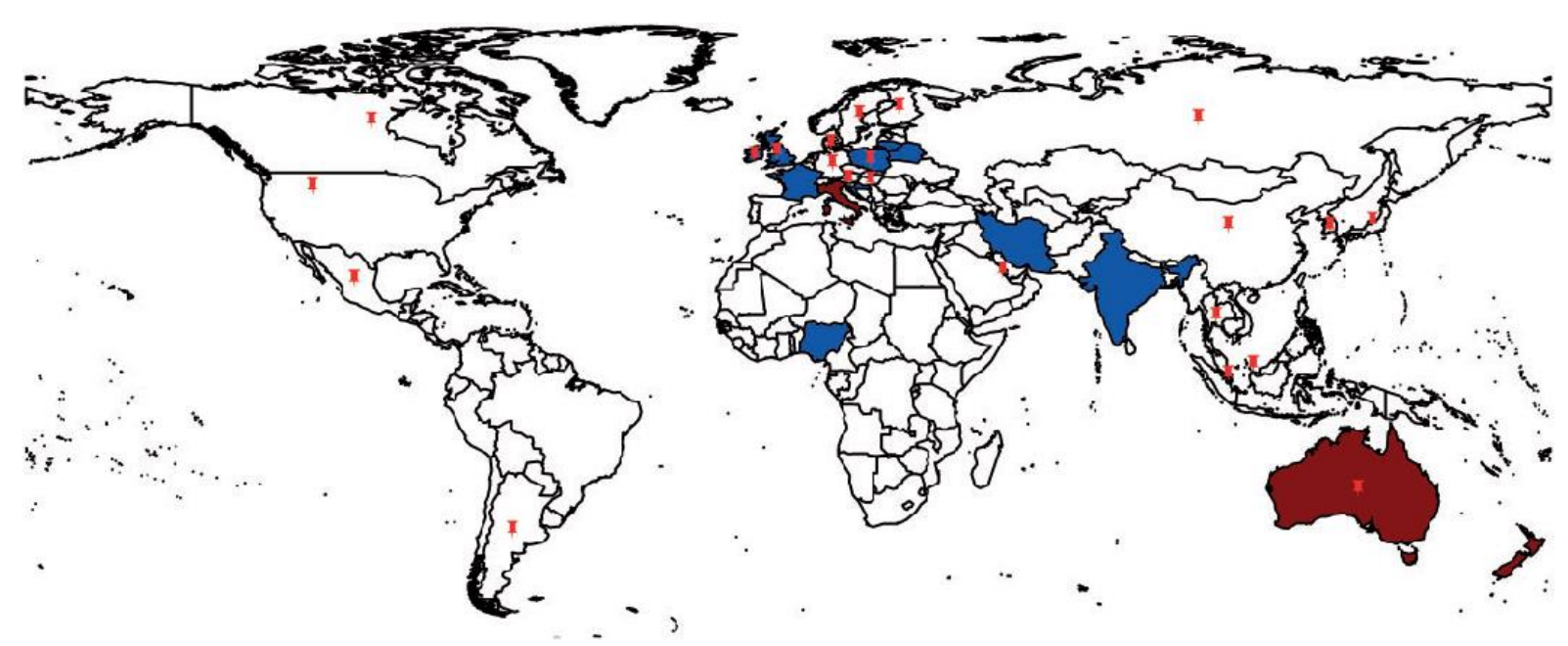

Figure 16. World map showing availability of studies with gender-specific incidence and national registries (pins). These include studies with either crude incidence and/or adjusted incidence figures irrespective of age restriction, or adjustment method.

\section{Conclusion}

In this updated data summary, we suggest that there is much that can be learned from countries that are managing to keep stroke incidence, case-fatality and mortality rates at low levels relative to othercountries with similar demographic or socioeconomic circumstances. We further highlight the growing trend for national clinical registries to provide such estimates for stroke in lieu of community-based incidence studies.

\section{Author contributions}

AGT contributed to conception and design of the study, undertook the data analyses, wrote parts of the first draft of the manuscript and approved the final version.

TT undertook the literature search and data collection, wrote parts of the first draft of the manuscript and approved the final version.

GH contributed to the design of the study, undertook some of the analyses, interpreted the data, revised the manuscript, and approved the final version.

$\mathrm{VJH}$ contributed to the design of the study, interpreted the data, revised the manuscript, and approved the final version.

PMH contributed to the design of the study, interpreted the data, revised the manuscript, and approved the final version.

VLF interpreted the data, revised the manuscript, and approved the final version.

BN interpreted the data, revised the manuscript, and approved the final version.

GAD contributed to conception and design of the study, wrote parts of the first draft of the manuscript and approved the final version.

DAC contributed to conception and design of the study, wrote parts of the first draft of the manuscript and approved the final version.

\section{Acknowledgements}


The source of the mortality data is the World Health Organization (WHO) Mortality database, and the WHO is responsible only for the provision of the original information. The analyses, interpretations, and conclusions are the authors alone not to the WHO. The authors thankDoreen Busingye, PhD (Stroke and Ageing Research, Monash University), as a contributor for preparing Figures 2, 3, 15, and 16 using ArcMap.

\section{Declaration of conflicting inte rests}

The author(s) declared no potential conflicts of interest with respect to the research, authorship, and/or publication of this article.

\section{Funding}

The author(s) disclosed receipt of the following financial support for the research, authorship, and/or publication of this article: The following authors receive Research Fellowship support from the National Health and Medical Research Council: Dominique Cadilhac (1063761; co-funded by Heart Foundation) and Amanda Thrift (1042600). Tharshanah Thayabaranathan received an Australian Postgraduate Award.

\section{References}

1. Thrift AG, Cadilhac DA, Thayabaranathan T, et al. Global stroke statistics. Int J Stroke 2014; 9(1): 618.

2. Feigin VL, Norrving B, George MG, Foltz JL, Roth GA and Mensah GA. Prevention of stroke: A strategic global imperative. Nat Rev Neurol 2016; 12(9): 501-512.

3. Feigin VL, Roth GA, Naghavi M, et al. Global burden of stroke and risk factors in 188 countries, during 1990-2013: A systematic analys is for the Global Burden of Disease Study 2013. Lancet Neurol 2016; 15(9): 913-924.

4. Cadilhac DA, Kim J, Lannin NA, et al. National stroke registries for monitoring and improving the quality of hospitalcare: A systematic review. Int J Stroke 2016; 11(1): 28-40.

5. Ahmad OB, Boschi-Pinto C, Lopez AD, Murray CJL, Lozano R and Inoue M. Age standardization of rates: A new WHO world standard.Geneva: World Health Organization, 2001 (GPE discussion paper series: No. 31; downloadable from www.who.int/whosis/indicators/ compendium/2008/1 mst/en/, accessed 6 January 2010.

6. Cantu-Brito C, Majersik JJ, Sanchez BN, et al. Door-to-door capture of incident and prevalent stroke cases in Durango, Mexico: The Brain Attack Surveillance in Durango Study. Stroke 2011; 42(3): 601606.

7. Corso G, Bottacchi E, Giardini G, et al. Epidemiology of stroke in Northern Italy: The Cerebrovascular Aosta Registry, 2004-2008. Neurol Sci 2012; 34(7): 1071-1081.

8. Danesi MA, Okubadejo NU, Ojini FI and Ojo OO. Incidence and 30-day case fatality rate of first-ever stroke in urban Nigeria: The prospective community based Epidemiology of Stroke in Lagos (EPISIL) phase II results. J Neurol Sci 2013; 331(1): 43-47.

9. El-Tallawy HN, Farghaly WMA, Shehata GA, et al. Epidemiology of non-fatal cerebrovascular stroke and transient ischemic attacks in Al Quseir, Egypt. Clin Interventions Aging 2013; 8: 1547-1551.

10. Feigin VL, Krishnamurthi RV, Barker-Collo S, et al. 30-year trends in stroke rates and outcome in Auckland, New Zealand (1981-2012): A multi-ethnic population-based series of studies. PLoS ONE 2015; 10(8): e0134609.

11. Khealani BO, Hameed B and Mapari UU. Stroke in Pakistan. J Pakistan Med Assoc 2008; 58(7): 400403.

12. Leyden JM, Kleinig TJ, Newbury J, et al. Adelaide stroke incidence study: Declining stroke rates but many preventable cardioembolic strokes. Stroke 2013; 44(5): 1226-1231.

13. Maredza M, Bertram MY and Tollman SM. Disease burden of stroke in rural South Africa: An estimate of incidence, mortality and disability adjusted life years. BMC Neurol 2015; 15(1): 1-12.

14. Olindo S, Chausson N, Mejdoubi M, et al. Trends in incidence and early outcomes in a black Afro Caribbean population from 1999 to 2012: Etude Re' alise' e en Martinique et Centre' e sur l'Incidence des Accidents Vasculaires Ce' re' braux II Study. Stroke 2014; 45(11): 3367-3373. 
15. Omama S, Yoshida Y, Ogasawara K, et al. Incidence rate of cerebrovascular diseases in Northern Japan determined from the Iwate Stroke Registry with an inventory survey system. $J$ Stroke Cerebrovasc Dis 2013; 22(8): e317-e322.

16. Ramalle-Go mara E, Ruiz E, Serrano M, Bartulos M, Gonzalez M-A' and Matute B. Hospital discharges and mortality registries: 2. Complementary databases for the epidemiological surveillance of stroke. J Stroke Cerebrovasc Dis 2013; 22(8): e441-e445.

17. Demant MN, Andersson C, Ahlehoff O, et al. Temporal trends in stroke admissions in Denmark 19972009. BMC Neurol 2013; 13(1): 1-8.

18. Azarpazhooh MR, Etemadi MM, Donnan GA, et al. Excessive incidence of stroke in Iran: Evidence from the Mashhad Stroke Incidence Study (MSIS), a population-based study of stroke in the Middle East. Stroke 2010; 41: e3-e10.

19. Corbin DOC, Poddar V, Hennis A, et al. Incidence and case fatality rates of first-ever stroke in a black Caribbean population: The Barbados Register of Strokes. Stroke 2004; 35(6): 1254-1258.

20. Corso G, Bottacchi E, Giardini G, et al. Community-based study of stroke incidence in the Valley of Aosta, Italy. CARe - cerebrovascular Aosta Registry: Years 2004-2005. Neuroepidemiology 2009; 32(3): 186-195.

21. Feigin VL, Lawes CM, Bennett DA and Anders on CS. Stroke epidemiology: A review of population based studies of incidence, prevalence, and case-fatality in the late 20th century. Lancet Neurol 2003; 2(1): 43-53.

22. Feigin VL, Lawes CM, Bennett DA, Barker-Collo SL and Parag V. Worldwide stroke incidence and early case fatality reported in 56 population-based studies: A systematic review. Lancet Neurol 2009; 8(4): 355-369.

23. Kelly PJ, Crispino G, Sheehan O, et al. Incidence, event rates, and early outcome of stroke in Dublin, Ireland: The North Dublin Population Stroke Study. Stroke 2012; 43(8): 2042-2047.

24. Kulesh SD, Filina NA, Frantava NM, et al. Incidence and case-fatality of stroke on the east border of the European Union. Stroke 2010; 41: 2726-2730.

25. Pikija S, Cvetko D, MalojèiéB, et al. A population-based prospective 24-month study of stroke: Incidence and 30-day case-fatality rates of first-ever strokes in Croatia. Neuroepidemiology 2012; 38(3): 164-171.

26. Sienkiewicz-Jarosz H, Gluszkiewicz M, Pniewski J, et al. Incidence and case fatality rates of first-ever stroke - Comparis on of data from two prospective population-based studies conducted in Warsaw. Neurologia I Neurochirurgia Polska 2011; 45(3): 207-212.

27. Sugama C, Isa K, Okumura K, Iseki K, Kinjo K and Ohya Y. Trends in the incidence of stroke and cardiovascular risk factors on the isolated island of Okinawa: The Miyakojima Study. $J$ Stroke Cerebrovasc Dis 2013; 22(7): e118-e123.

28. The European Registers of Stroke Investigators. Incidence of stroke in Europe at the beginning of the 21st century. Stroke 2009; 40(5): 1557-1563.

29. Zhang Y, Chapman AM, Plested M, Jackson D and Purroy F. The incidence, prevalence, and mortality of stroke in France, Germany, Italy, Spain, the UK, and the US: A literature review. Stroke Res Treatment 2012; 2012: 436125.

30. Benamer HT and Grosset D. Stroke in Arab countries: A systematic literature review. J Neurol Sci 2009; 284(1-2): 18-23.

31. Sridharan SE, Unnikrishnan JP, Sukumaran S, et al. Incidence, types, risk factors, and outcome of stroke in a developing country: The Trivandrum Stroke Registry. Stroke 2009; 40(4): 1212-1218.

32. Owolabi M. Taming the burgeoning stroke epidemic in Africa: Stroke quadrangle to the rescue. West Indian Med J 2011; 60: 412-421.

33. Connor MD, Walker R, Modi G and Warlow CP. Burden of stroke in black populations in sub-Saharan Africa. Lancet Neurol 2007; 6(3): 269-278.

34. Bejot Y, Osseby GV, Aboa-Eboule C, et al. Dijon's vanishing lead with regard to low incidence of stroke. Eur J Neurol 2009; 16(3): 324-329.

35. Vega T, Zurriaga O, Ramos JM, et al. Stroke in Spain: Epidemiologic incidence and patterns: A health sentinel network study. J Stroke Cerebrovasc Dis 2009; 18(1): 11-16. 
36. Jiang B, Wang WZ, Chen $\mathrm{H}$, et al. Incidence and trends of stroke and its subtypes in China: Results from three large cities. Stroke 2006; 37(1): 63-68.

37. Syme PD, Byrne AW, Chen R, Devenny R and Forbes JF. Community-based stroke incidence in a Scottish population: The Scottish Borders Stroke Study. Stroke 2005; 36(9): 1837-1843.

38. Minelli C, Fen LF and Minelli DP. Stroke incidence, prognosis, 30-day, and 1-year case fatality rates in Matao, Brazil: A population-based prospective study. Stroke 2007; 38(11): 2906-2911.

39. Sajjad A, Chowdhury R, Felix JF, et al. A systematic evaluation of stroke surveillance studies in lowand middle-income countries. Neurology 2013; 80(7): 677-684.

40. Ray BK, Hazra A, Ghosal M, et al. Early and delayed fatality of stroke in Kolkata, India: Results from a 7-year longitudinal population-based study. J Stroke Cerebrovasc Dis 2013; 22(4): 281-289.

41. Anders on CS, Jamrozik KD, Burvill PW, Chakera TM, Johnson GA and Stewart-Wynne EG. Ascertaining the true incidence of stroke: Experience from the Perth Community Stroke Study, 19891990. Med J Aust 1993; 158(2): 80-84.

42. Appelros P, Nydevik I, Seiger A and Terent A. High incidence rates of stroke in Orebro, Sweden: Further support for regional incidence differences within Scandinavia. Cerebrovasc Dis 2002; 14: 161168.

43. Benatru I, Rouaud O, Durier J, et al. Stable stroke incidence rates but improved case-fatality in Dijon, France, from 1985 to 2004. Stroke 2006; 37(7): 1674-1679.

44. Bonita R, Broad JB and Beaglehole R. Changes in stroke incidence and case-fatality in Auckland, New Zealand, 1981-91. Lancet 1993; 342(8885): 1470-1473.

45. Carolei A, Marini C, Di Napoli M, et al. High stroke incidence in the prospective community-based L'Aquila registry (1994-1998). First year's results. Stroke 1997; 28: 2500-2506.

46. Di Carlo A, Inzitari D, Galati F, et al. A prospective community-based study of stroke in southern Italy: The Vibo Valentia incidence of stroke study (VISS). Methodology, incidence and case fatality at 28 days, 3 and 12 months. Cerebrovasc Dis 2003; 16: 410-417.

47. Du X, Sourbutts J, Cruickshank K, et al. A community based stroke register in a high risk area for stroke in north west England. J Epidemiol Community Health 1997; 51: 472-478.

48. Janes F, Gigli GL, D'Anna L, et al. Stroke incidence and 30-day and six-month case fatality rates in Udine, Italy: A population-based prospective study. Int J Stroke 2013; 8(Suppl A100): 100-105.

49. Kolominsky-Rabas PL, Sarti C and Heuschmann PU. A prospective community-based study of stroke in Germany. The Erlangen stroke project (ESPro): Incidence and case fatality at 1, 3, and 12 months. Stroke 1998; 29: 2501-2506.

50. Thrift AG, Dewey HM, Sturm JW, et al. Incidence of stroke subtypes in the North East Melbourne Stroke Incidence Study (NEMESIS): Differences between men and women. Neuroepidemiology 2009; 32(1): 11-18.

51. Vemmos KN, Bots ML, Tsibouris PK, et al. Stroke incidence and case fatality in southern Greece: The Arcadia stroke registry. Stroke 1999; 30(2): 363-370.

52. AshokPP, Radhakrishnan K, Sridharan R and el-Mangoush MA. Incidence and pattern of cerebrovascular diseases in Benghazi, Libya. J Neurol Neurosurg Psychiatry 1986; 49(5): 519-523.

53. Correia M, Silva MR, Matos I, et al. Prospective-community based study of stroke in Northern Portugal: Incidence and case fatality in rural and urban populations. Stroke 2004; 35(9): 2048-2053.

54. D’Alessandro G, Di Giovanni M, Roveyaz L, et al. Incidence and prognos is of stroke in the Valle d'Aosta Italy. Stroke 1992; 23: 1712-1715.

55. Feigin VL, Wiebers DO, Whisnant JP and O'Fallon WM. Stroke incidence and 30-day case-fatality rates in Novosibirsk, Russia, 1982 through 1992. Stroke 1995; 26(6): 924-929.

56. Lauria G, Gentile M, Fassetta G, et al. Incidence and prognosis of stroke in the Belluno Province, Italy: First-year results of a community-based study. Stroke 1995; 26: 1787-1793.

57. Lavados PM, Sacks C, Prina L, et al. Incidence, 30-day case-fatality rate, and prognosis of stroke in Iquique, Chile: A 2-year community-based prospective study (PISCIS project). Lancet 2005; 365(9478): 2206-2215.

58. Musolino R, La Spina P, Serra S, et al. First-ever stroke incidence and 30-day case fatality in the Sicilian Aeolian Archipelago, Italy. Stroke 2005; 36(12): 2738-2741. 
59. Ricci S, Celani MG, La Rosa F, et al. SEPIVAC: A community-based study of stroke incidence in Umbria, Italy. J Neurol Neurosurg Psychiatry 1991; 54: 695-698.

60. Tsiskaridze A, Djibuti M, van MG, et al. Stroke incidence and 30-day case-fatality in a suburb of Tbilisi: Results of the first pros pective population-based study in Georgia. Stroke 2004; 35(11): $2523-$ 2528.

61. A s berg KH and Parrow A. Event, incidence, and fatality rates of cerebrovasculardiseases in Enköping-Hâbo, Sweden, 1986-1988. ScandJ Pub Health 1991; 19(2): 134-139.

62. Morikawa Y, Nakagawa H, Naruse Y, et al. Trends in stroke incidence and acute case fatality in a Japanese rural area: The Oyabe study. Stroke 2000; 31(7): 1583-1587.

63. Vibo R, Korv $\mathbf{J}$ and Roose M. The third stroke registry in Tartu, Estonia: Decline of stroke incidence and 28-day case-fatality rate since 1991. Stroke 2005; 36: 2544-2548.

64. Feigin VL, Forouzanfar MH, Krishnamurthi R, et al. Global and regional burden of stroke during 1990-2010: Findings from the Global Burden of Disease Study 2010. Lancet 2014; 383(9913): 245254.

65. Sudlow CL and Warlow CP. Comparing stroke incidence worldwide: What makes studies comparable? Stroke 1996; 27(3): 550-558.

66. Lindsay P, Furie KL, Davis SM, Donnan GA and Norrving B. World Stroke Organization global stroke services guidelines and action plan. Int J Stroke 2014; 9(Suppl A100): 4-13.

67. Feigin VL, Krishnamurthi R, Bhattacharjee R, et al. New strategy to reduce the global burden of stroke. Stroke 2015; 46(9): 1740-1747.

68. Tse T, Carey L, Cadilhac D, Koh GC-H and Baum C. Application of the World Stroke Organization health systemindicators and performance in Australia, Singapore, and the USA. Int J Stroke 2016; 11(10): 852-859.

69. Marti-Vilalta JL and Arboix A. The Barcelona Stroke Registry. Eur Neurol 1999; 41(3): 135-142.

70. Asplund K, Hulter Asberg K, Appelros P, et al. The Riks -Stroke story: Building a sustainable national register for quality assessment of stroke care. Int J Stroke 2011; 6(2): 99-108.

71. KobayashiS. International experience in stroke registry: Japanese Stroke Databank. Am J Prev Med 2006; 31(6, Supplement 2): S240-S242.

72. Truelsen T, Krarup LH, Iversen HK, et al. Causes of death data in the Global Burden of Disease: Estimates for ischemic and hemorrhagic stroke. Neuroepidemiology 2015; 45(3): 152-160.

73. Heidrich J, Heuschmann PU, Kolominsky-Rabas P, Rudd AG and Wolfe CDA. Variations in the use of diagnostic procedures after acute stroke in Europe: Results from the BIOMED II study of stroke care. Eur J Neurol 2007; 14(3): 255-261.

74. Wolfe CD, Tilling K, Beech R and Rudd AG. Variations in case fatality and dependency from stroke in western and central Europe. The European BIOMED Study of Stroke Care Group. Stroke 1999; 30: 350-356.

75. Abdul-Ghaffar NU, El-Sonbaty MR, el-Din Abdul-Baky MS, Marafie AA and al-Said MM. Stroke in Kuwait: A three-year prospective study. Neuroepidemiology 1997; 16: 40-47.

76. Rastenyte D, Sopagiene D, Virviciute D and Juriene K. Diverging trends in the incidence and mortality of stroke register in Kaunas, Lithuania. Scand J Pub Health 2006; 34: 488-495.

77. Powles J, Kirov P, Feschieva N, Stanoev M and Atanasova V. Stroke in urban and rural populations in north-east Bulgaria: Incidence and case-fatality findings from a 'hot pursuit' study. BMC Public Health 2002; 2: 24.

78. Das SK, Banerjee TK, Biswas A, et al. A prospective community-based study of stroke in Kolkata, India. Stroke 2007; 38(3): 906-910. 